\title{
Radon Gas Measurements through Geiger and Sodium Iodide Scintillator-Study Efficiency Comparison
}

\author{
Inacio Malmonge Martin and Marcelo Pego Gomes \\ Physics Department, Technological Institute of Aeronautics—ITA, São José dos Campos, SP 12228-900, Brazil
}

\begin{abstract}
With the use of a Geiger proportional counter with sensor tube of Russian and Chinese origin, a comparison was made in this work between measurements of environmental ionizing radiation with these detectors and a sodium iodide scintillator activated with TI (Thallium NaI). Through measurements carried out in a room located inside a tower 25 meters high on the ITA (Technological Institute of Aeronautics) campus, it was possible to study the efficiency of the three instruments for the environmental measurement of ionizing radiations at that location. Between March 7th and June 2nd of 2017, in that region, nine intense and weak rains were observed with 12 cold fronts coming from southern Brazil. Radiation measurements and the local meteorology involved are analyzed in this work to verify possible correlations.
\end{abstract}

Key words: Ionizing radiation, rain, radon gas.

\section{Introduction}

Anywhere near the earth's surface, the low energy ionizing radiation up to $10.0 \mathrm{MeV}$ is practically all coming from the exhalation of radon gas from the earth's crust [1]. Radon gas comes from the decay of ${ }^{238} \mathrm{U}$ present on earth since its formation. Radioactive elements such as uranium, thorium and potassium are found in almost all types of rocks, sands, soils and water [2]. The radium ${ }^{226} \mathrm{Ra}$ and its decay products are responsible for a major fraction of the dose of internal emissions received by humans [3]. ${ }^{226} \mathrm{Ra}$ has a half-life of 1,600 years, and decays to radon ${ }^{222} \mathrm{Rn}$, which has a half-life of 3.82 days. The decay of ${ }^{222} \mathrm{Rn}$ is followed by successive disintegration of short half-life alpha, beta and gamma emitters. After decay stages, the radioactive chain ends with stable lead ${ }^{206} \mathrm{~Pb}$. With regard to soils and rocks, the ${ }^{226} \mathrm{Ra}$ is present in virtually all soils and rocks in varying amounts. Areas with high levels of background radiation found in some soils are due to geological conditions and geochemical effects and cause

Corresponding author: Inacio Malmonge Martin, Ph.D., main research fields: ionization radiation, solar physics and earth atmosphere. increased terrestrial radiation. Researches in the world, and specifically in Brazil, show these conditions [4]. The isotope ${ }^{222} \mathrm{Rn}$, with a half-life of approximately 3.82 days, has a greater opportunity than the short half-life isotopes of escaping the atmosphere. The great importance attributed to this isotope in relation to human exposure is related to the fact that it has a longer half-life [5]. Several studies report variations throughout the day of radon concentrations. Maximum concentrations are observed in the first hours of the day and the lowest values are found late in the afternoon, when concentrations are about one third of morning values. Over the course of a year, the ${ }^{222} \mathrm{Rn}$ levels tend to peak in the fall or winter months and have lows in the spring. This variation is consistent with atmospheric turbulence patterns, which tend to be higher in the spring [6]. However, it is likely that variations in concentrations in localities are dependent on local meteorological factors (rain, wind, temperature, pressure, etc.) which influence the rate of exhalation of the soil gases and dispersion in the atmosphere. Thus, the exhalation rate of the soil can increase during periods when the atmospheric pressure decreases. The fraction of radon atoms released by the radium in the pores of rocks and soil is called the 
emanation coefficient. The factors influencing this coefficient are related to the grain size, which determines how much radium is close enough to the surface to allow radon to escape into the pores. In general, the radon emanation factor is inversely proportional to the grain size [7]. Radon emanation is also related to grain density, their porosity and the partition coefficient between air and water, which is the ratio between the concentrations of radon in air and water.

\section{Material and Methods}

According to Tell, I., et al. [5], more than $60 \%$ of the radon found in indoor environments comes from the soil of the foundation and the soils around the building. Based on this experimental claim and knowing that radon decays into particles $\alpha$ followed by gamma radiation, both of energy lower than 10.0 $\mathrm{MeV}$, in this work, it was decided to monitor the variation of gamma radiation at the site [8].

For the measurements, a Geiger with a type STS-6 pipe, made in Russia, was used and a Geiger with a type J305 from Radiation D-v1.1 (Cajoe-Electronics Co., Ltd.) made in China, both powered with high voltage using a circuit from the Arduino system [9]. The same circuit of the Arduino system was used to acquire the measures of both Geigers with a unit of time of one minute between each measure. Fig. 1 shows this system is monitoring the environmental ionizing radiation in a room of the Department of Physics of ITA (Technological Institute of Aeronautics). The laptop seen in Fig. 1 is required to record and save measurements during long-running series of about 6 months or longer duration.

Based on the principle of scintillation in inorganic crystals, a Thallium-doped sodium iodide detector of 3 inches high by 3 inches in diameter $(3$ " $\times 3$ ") was used. This crystal directly coupled to a photomultiplier enables measuring scintillations that the gamma radiation causes on the crystal. The crystal and photomultiplier system is kept rigidly attached by a very thin metallic cover, as seen in Fig. 2a. The associated electronics of the photomultiplier power supply and data acquisition was bought at the Ludlum American Company with the channel versus energy calibration already performed. A laptop is attached to this system to record and save measurements in long series in the tower (Fig. 2b).

\section{Results and Discussions}

The series of gamma radiation measurements integrated between 0.2 and $10.0 \mathrm{MeV}$ during 07/03 and $02 / 06$ of 2017, in intervals of minutes, can be seen in Fig. 3. The peaks in the range of observed gamma radiation represent the presence of rain in this time interval. According to the measurements of gamma radiation, it indicates that there were nine peaks in all of the intervals considered. After the arrival of each rainfall, there is a reasonable increase of the present gamma radiation. Soon after, this intensity decreases reaching the lowest level, which again begins to increase with time until the arrival of the next rain or cloud cover. This is the dynamic of time of a cold front arriving in the region. Observing the graph of the intensity of ionizing radiation over time in Fig. 3, it is possible to note nine peaks of rain and nine ramps relative to the dynamics of cold front passage in the region.

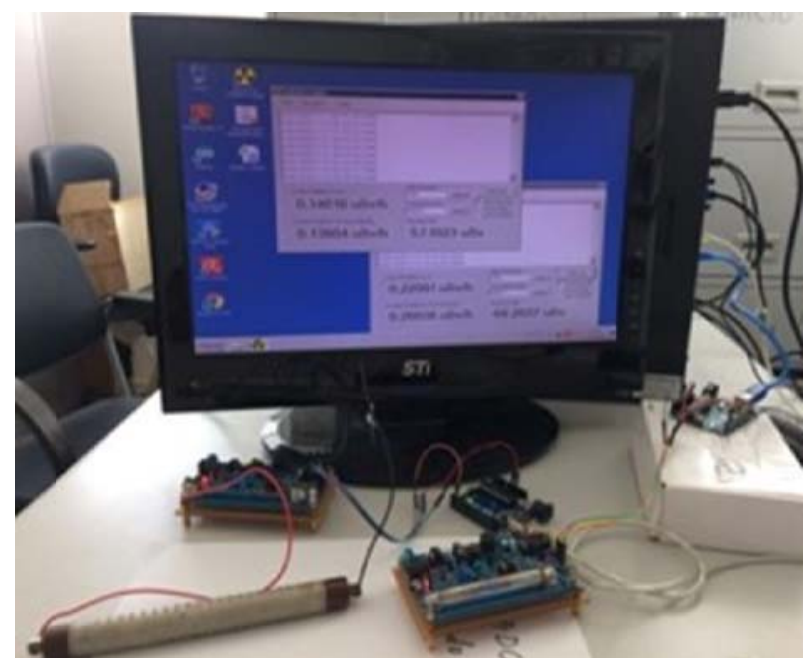

Fig. 1 Russian and Chinese Geiger tube with Arduino electronics and PC (Personal Computer). 


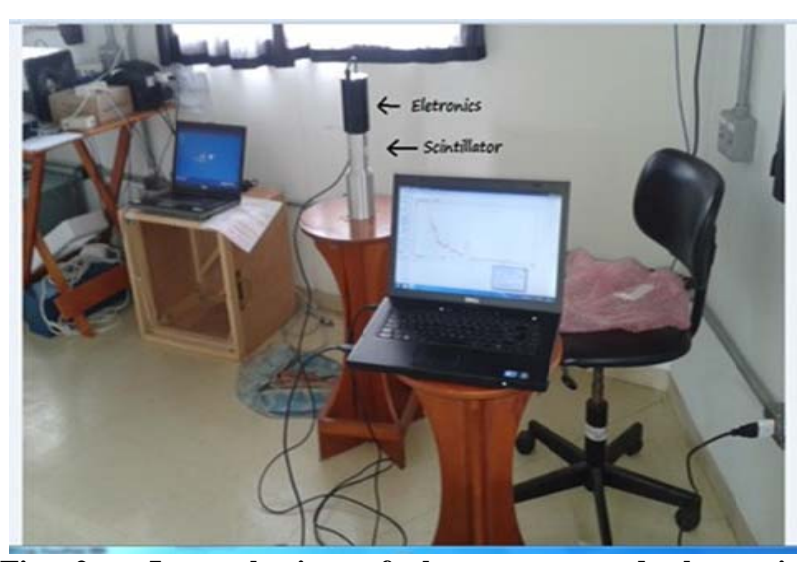

Fig. 2a Internal view of the gamma and electronic detector associated with $\mathrm{PC}$ in the tower room at 25 meters above ground level.

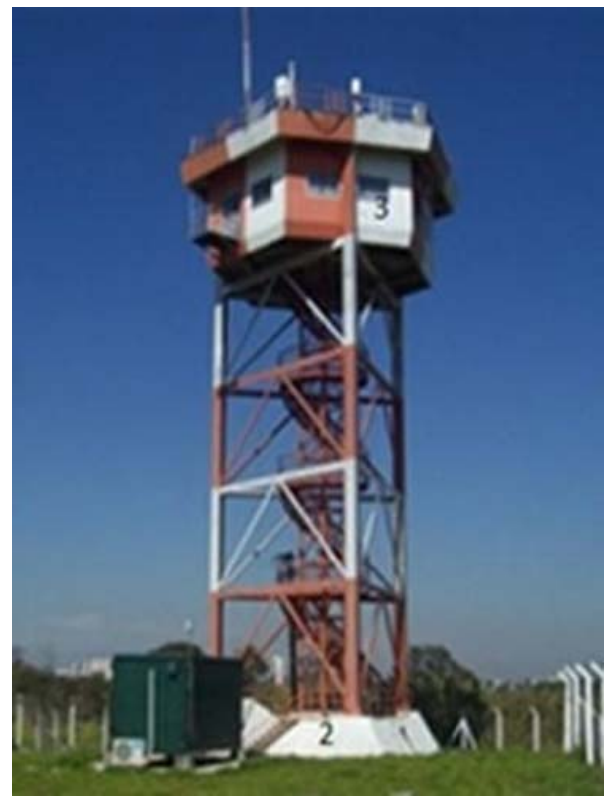

Fig. 2b Exterior view of the room in the tower.
The detail of the highest peak radiation measured from the above series located around $72 \times 10^{3}$ minutes can be expanded to verify details of the dynamics of the radiation as shown in Fig. 4.

Enlarging once again the graph of Fig. 4 around the same time as Fig. 5, further details are given.

This phenomenon always occurs when the intensity of rain that arrived at the site is greater than or equal to $0.4 \mathrm{~mm} / \mathrm{min}$. The transformation between dose of radiation $\mu \mathrm{Sv} / \mathrm{h}$ is related to $\mathrm{Bq} / \mathrm{m}^{3}$ of the radon gas through Eq. (1) [10].

$(\mu \mathrm{Gy} / \mathrm{h})=0.3857+0.000866$ Radon $\left(\mathrm{Bq} / \mathrm{m}^{3}\right)(1)$

In these measurements, a day/night periodicity (green line) is observed, indicating the significant presence of the radon gas in the region. During the daytime, there is greater exhalation of the gas from earth and consequently higher intensity of radiation present at the site. While at night, this phenomenon is reversed.

In the case of the Geiger with Chinese tube, the same phenomenon is observed but with less precision. Fig. 6 shows the spectrum in intensity and time of the precipitated rainfall, in the interval of $15 / 03$ to $02 / 06$ of 2017 , in the same place as the radiation detectors.

Comparing Figs. 3, 7 and 8, it is possible to notice through Fig. 6 a good correlation between rainfall and gamma radiation measured by the sodium iodide scintillator shown in Fig. 3.

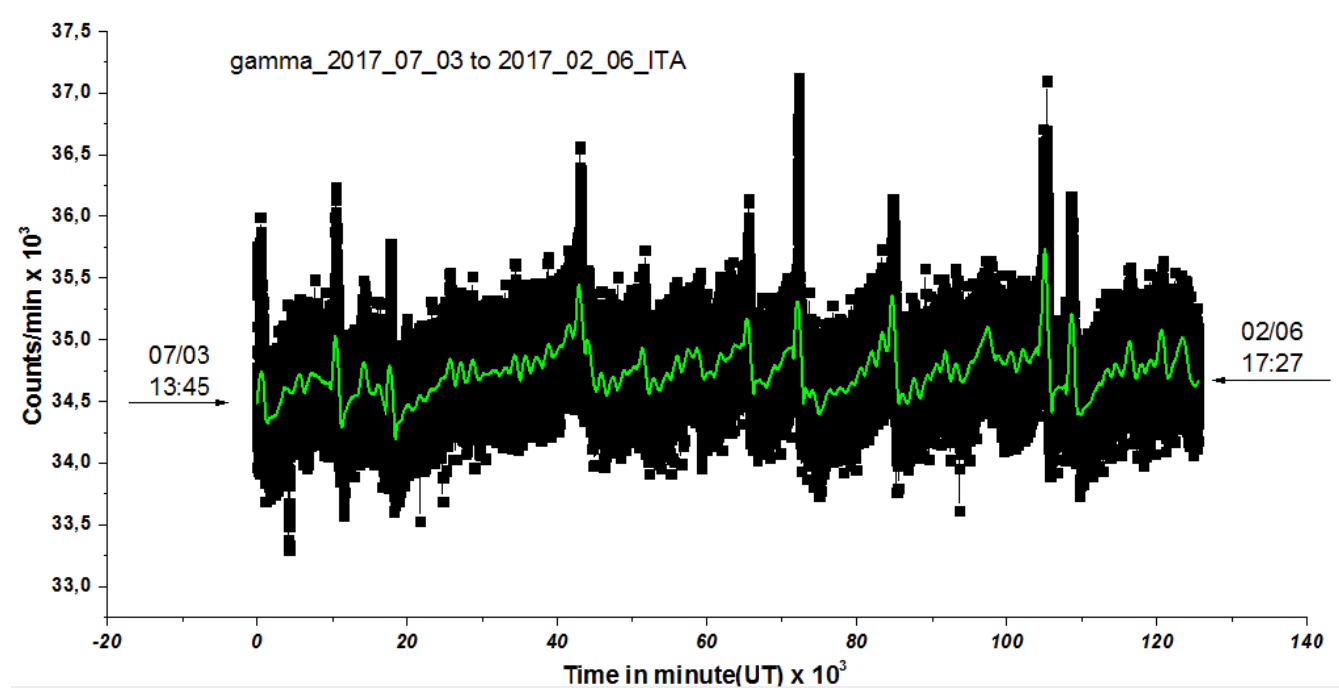

Fig. 3 Graph of the radiation measurement showing the presence of rains (9) and cold fronts passages (9) in the region. 


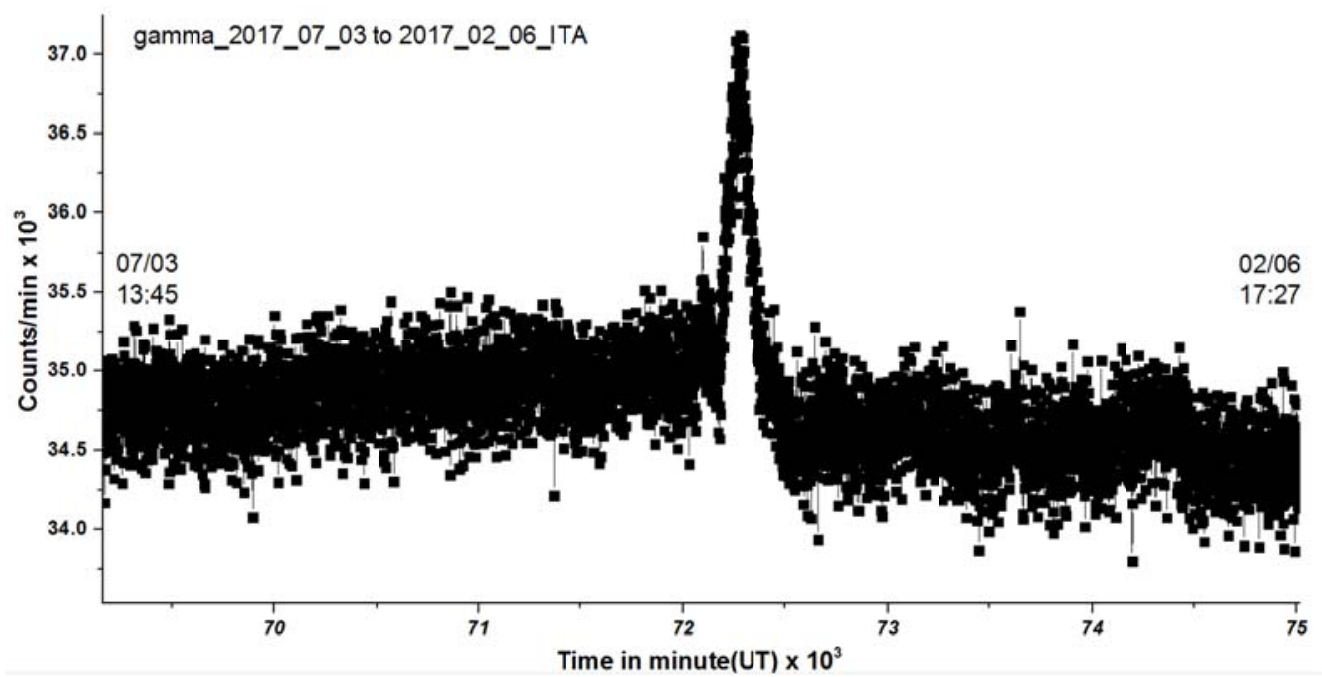

Fig. 4 Detailed view of radiation intensity around $72 \times 10^{3}$ minutes.

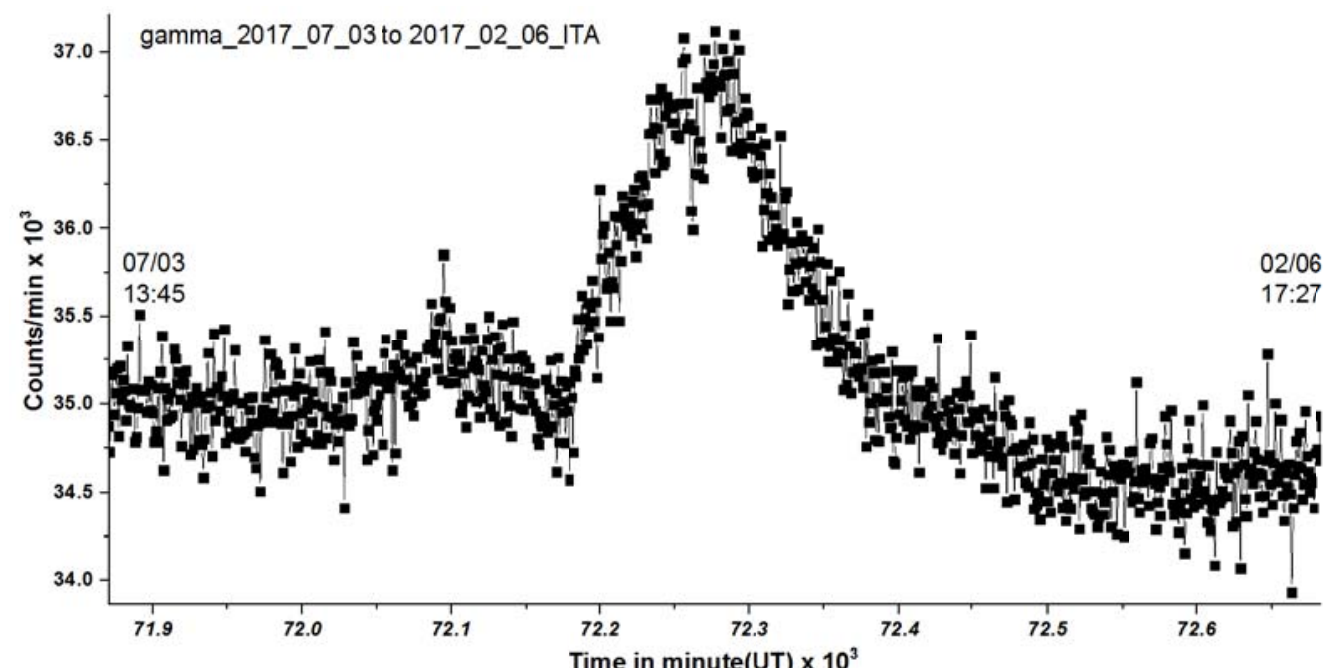

Fig. 5 Double magnification of the measurement of radiation around $72 \times 10^{3}$ showing the arrival phase of the rain and the decay of it.

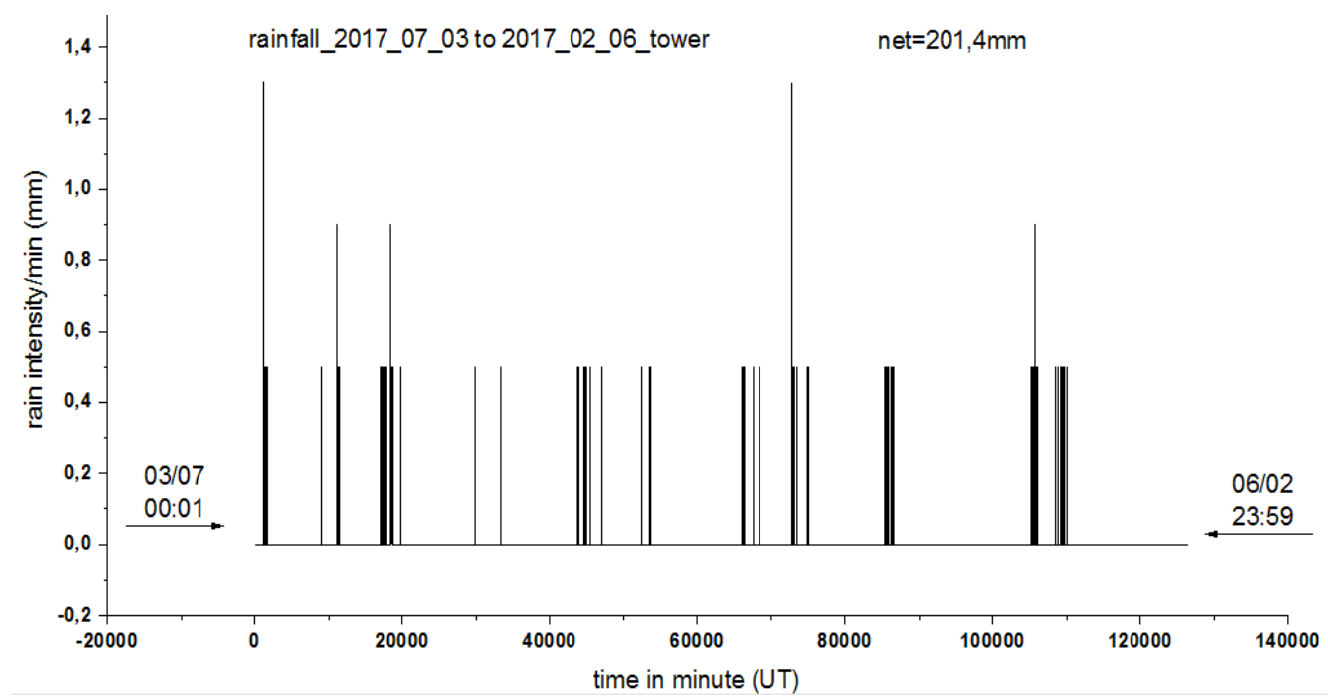

Fig. 6 Measurement of the rainfall intensity every minute at the same place where the radiation detectors are located. 


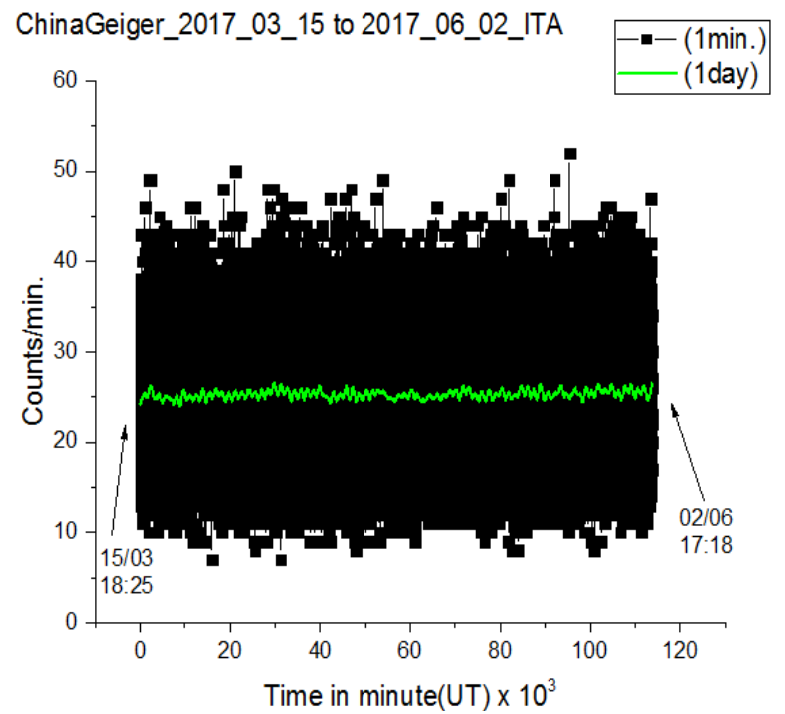

Fig. 7 Count rate per minute made by Geiger with Chinese tube.

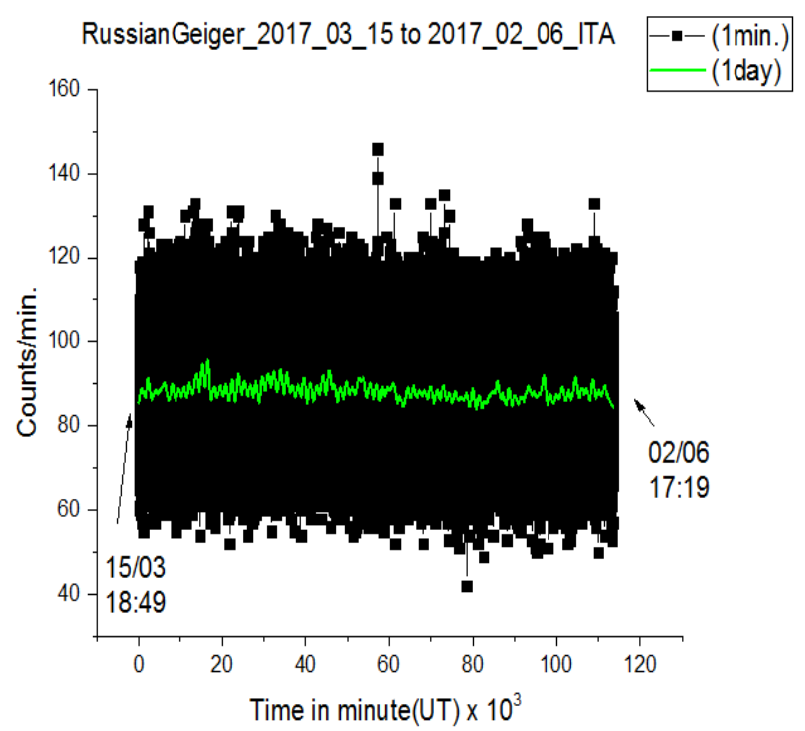

Fig. 8 Count rate per minute made by Geiger with Russian tube.

\section{Conclusion}

It was verified in this study the differences present in environmental ionizing radiation when it is measured by Geiger counters and sodium iodide scintillators. The ideal way to verify rainfall measured close to the ground is to use a scintillator of ( 3 " $\times 3$ ") inches and measure all gamma radiation in the range of $200 \mathrm{keV}$ and $10.0 \mathrm{MeV}$. Geiger counters existing in international trade of various dimensions present greater difficulty in seeing rainfall through radiation measurements. However, they can detect the day/night variation caused by the release of radon gas with alpha, beta and gamma radiation decays.

\section{Acknowledgment}

Thanks to CNPq (National Counsel of Technological and Scientific Development) and CAPES (Coordination for the Improvement of Higher Education Personnel) by the fellowships grants support to the group's researchers and the ITA Division of Fundamental Sciences for supporting this research.

\section{References}

[1] Martin, I. M., Gomes, M. P., Ferro, M. A., and Silva, F. A. 2017. "Correlations between Rainfall and Cold Fronts with Gamma Rays Measurements near the Ground Level in Southeast of Brazil." Journal of Environmental Science and Engineering B 6: 115-20.

[2] Correa, J. N. 2011. "Evaluation of Radon Concentration Levels in Environments and Waters of Wells in the State of Paraná." Ph.D. thesis, Federal Technological University of Parana, Campus of Curitiba, Brazil, in Postgraduate Program in Electrical Engineering and Industrial Informatics.

[3] Espinosa, G., and Golzarri, J. I. 2017. "Radon and Thoron $\left({ }^{222} \mathrm{Rn}\right.$ and $\left.{ }^{220} \mathrm{Rn}\right)$ Concentration Distribution Study on Three Detection Planes inside of a Closed Room Using Nuclear Track Methodology." Journal of Environmental Science and Engineering A 6: 149-54. doi:10.17265/2162-5298/2017.03.006.

[4] Furrer, D., Crameri, R., and Burkart, W. 1991. "Dynamics of Rn Transport from the Cellar to the Living Area in an Unheated House." Health Physics 60 (3): 393-8.

[5] Tell, I., Bensryd, I., Rylander, L., Jonsson G., and Daniel, E. 1994. "Geochemistry and Ground Permeability as Determinants of Indoor Radon Concentrations in Southernmost Sweden." Applied Geochemistry 9 (6): 647-55.

[6] Fujiyoshi, R., Sakamoto, K., Imanishi, T., Sumiyoshi, T., Sawamura, S., Vaupotic, J., et al. 2006. "Meteorological Parameters Contributing to Variability in ${ }^{222} \mathrm{Rn}$ Activity Concentrations in Soil Gas at a Site in Sapporo, Japan." Sci. Total Environ. 370 (1): 224-34.

[7] Varley, N. R., and Flowers, A. G. 1998. "The Influence of Geology on Radon Levels in SW England.” Radiation Protection Dosimetry 77 (3): 171-6. 
[8] Ravisankar, R., Vanasundari, K., Chandrasekaran, A., Rajalakshmi, A., Suganya, M., Vijayagopal, P., et al. 2012. "Measurement of Natural Radioactivity in Building Materials of Namakkal, Tamil Nadu, India using Gamma-Ray Spectrometry." Applied Radiation and Isotopes 70 (4): 699-704.

[9] Baciu, A. C. 2005. "Radon and Thoron Progeny
Concentration Variability in Relation to Meteorological Conditions at Bucharest (Romania)." J. Environ. Radioactivity 83 (2): 171-89.

[10] Silwal, N. S. 2012. "Assessment of Radon and Gamma in Taboshar Mining Site, Tajikistan." Master's thesis, Norwegian University of Life Science, Department of Plants Science. 